\title{
Reflection through the Eyes of Teacher Trainees: A Repositioning of the concept in the CELTA Course
}

\author{
Soumia Boumaza \\ Canterbury Christ Church University-UK
}

\begin{abstract}
:
Reflective practice has always been highlighted as an important concept in language teacher education, and quickly became a core component as well as an approach to effective teaching and learning. In terms of teacher education and language training programmes, it has generally been presented as a core component in such courses and has usually been varied in its uses. It also emerged as a crucial aspect in creating quality educators and teachers. However, there has always been a lack of consensus over what reflective practice means, and what it entails in different teaching and learning contexts. This has led to a difficulty in terms understanding how it operates, particularly, in teacher education courses. Based on both the literature underlying this concept and an interest to add to its understanding in the educational field, this paper sheds light on understanding the concept of reflection in the CELTA (Certificate of English language teaching to Adults) course through the eyes of teacher trainees. The study, thus, aims primarily at exploring CELTA trainees' perceptions of the concept and examining how reflection is conceptualised in such a course. To be able to generate meanings, reflection in this study has been looked at using a qualitative research methodology. In this sense, observations during two CELTA courses were conducted. Interviews with the CELTA trainees also took place by the end of each course. Observations were mainly concerned with the teaching practice and the feedback sessions taking place afterwards. Interviews, however, dealt with uncovering participants' views and perceptions of reflection. Both the observations and interviews allowed a closer look at what the participants' views are regarding reflection and as the research progressed, an understanding of how this concept is positioned in the course is generated. Based on the collected data, this paper will be concerned with presenting an initial analysis of the findings and delivering a general account of the participants' understandings of reflection.
\end{abstract}

Key words: Certificate of English language teaching to adults; language teacher education, reflective practice; participants' perceptions, teacher training programmes. 